\title{
A paradoxical sleep-dependent window for memory 53-56 h after the end of avoidance training
}

\author{
CARLYLE SMITH and CHRISTINE MACNEILL \\ Trent University, Peterborough, Ontario, Canada
}

\begin{abstract}
Sprague-Dawley rats $(N=56)$ were trained in a two-way shuttle shock-avoidance task $(50$ trials/day for 2 consecutive days). Subjects were then assigned to one of six paradoxical sleep deprivation (PSD) groups or a non-PSD control group. Each test group was subjected to PSD for one of the following 4-h periods: Hours 49-52, 53-56, 57-60, 61-64, 65-68, or 69-72 after the last training trial. Retesting was done 7 days after the end of training. Memory loss was observed when the PSD was applied between 53 and 56 hours after the end of training but nowhere else. It was concluded that a vulnerable window for memory, requiring PS, exists during Hours 53-56 after the end of training in the shuttle avoidance task.
\end{abstract}

Considerable evidence suggests a close relationship between paradoxical sleep (PS) and memory in animals (Bloch, 1970; Fishbein \& Gutwein, 1978; McGrath \& Cohen, 1978; Pearlman, 1979; Smith, 1985). In an extensive review of the literature (Smith, 1985), the concept of the PS window (PSW) was proposed. For a PSW to exist, two conditions must be met: (1) above-normal levels of PS must appear following learning, and (2) paradoxical sleep deprivation (PSD) applied when this extra PS would normally be expected results in memory deficits (Smith, 1985).

In a shuttle shock-avoidance study, PS increases appeared on the same day as the training sessions, then returned to normal levels after the 2 nd day of training. Surprisingly, PS again began to increase over normal levels on the 1st posttraining day, reaching a maximum 5 posttraining days later (Smith \& Lapp, 1986). In a second experiment, a PSW from Hours 9 to 12 was established during the first PS increase on the 1st training day (TD1) (Smith \& Lapp, 1986). In another study, an attempt was made to see whether the second increase in PS was important to memory. PSD was applied at various times from Posttraining Day 1 (PT1) to Posttraining Day 9 (PT9). It was discovered that $24 \mathrm{~h}$ of PSD applied 2 days (48-72 h) after the end of the last training trial in the shuttle shock-avoidance task resulted in marked memory deficits when the rats were retested 1 week later. PSD did not result in memory deficits when applied at any other time from PT1 to PT9. Thus it was clearly demonstrated that PS is important for memory of an avoidance task 48-72 $\mathrm{h}$ after the end of training (Smith \& Kelly, 1988).

Correspondence should be addressed to C. Smith, Department of Psychology, Trent University, Peterborough, ON, K9J 7 B8 Canada.
The aim of the present study was to examine this time period during Hours 48-72 to see if the size of the PSW was indeed $24 \mathrm{~h}$ or whether PSD applied for shorter periods of time would reveal a smaller PSW. It was hypothesized that a 4-h PSD application would be sufficient to produce the memory deficits previously seen in the time period from Hour $\mathbf{4 8}$ to Hour $\mathbf{7 2}$ following training in the shock-avoidance task. Furthermore, since it had been previously observed that the PS increases were cyclic and tended to appear at the same time each day (Smith \& Lapp, 1986; Smith, Young, \& Young, 1980), it was hypothesized that the most effective PSD time would be in the time period during Hours 57-60 following the last training trial. This time period would coincide, in terms of the 24-h clock (light:dark cycle), with the well-established PSW from Hour 9 to Hour 12 previously found in the same task (Smith \& Lapp, 1986).

Because the type of task, strain of animal, and number of training trials are all important to the timing and duration of the extra PS following learning (Smith, 1985), it was decided to follow the experimental situation used in the previous studies (Smith \& Lapp, 1986; Smith \& Kelly, 1988). In this way, the distribution of PS following learning would be known.

\section{METHOD}

\section{Subjects}

Naive male Sprague-Dawley rats $(N=56)$, raised at the Trent University animal facility and weighing $350-450 \mathrm{~g}$ at the time of training, were used. The rats were housed and tested in rooms with constant temperature and humidity. They lived in a 12:12-h light:dark cycle, with the lights on at 8:00 a.m.

\section{Apparatus, Procedure, and Groups}

The apparatus was a two-way shuttle shock-avoidance box with sides made of Plexiglas. The two compartments $(23 \mathrm{~cm}$ long $\times$ 
$9 \mathrm{~cm}$ wide $\times 23 \mathrm{~cm}$ high) were separated by a hand-operated sliding door. Each compartment had a light ( $28 \mathrm{~V}$, No. 313 lamp) in the roof, which served as the conditioned stimulus (CS). The grid floor was able to deliver a 1-mA scrambled shock when desired.

The procedure involved placing the rat in a darkened compartment of the apparatus. After $1 \mathrm{~min}$ of acclimatization, training trials were begun. The overhead light (CS) came on and the sliding door was opened. The rat had $10 \mathrm{sec}$ to move to the opposite dark compartment before the footshock came on. After the footshock, when the animal moved to the dark compartment, the door was shut and the $30-\mathrm{sec}$ intertrial interval was begun. At the end of the $30 \mathrm{sec}$, the light in the second compartment, where the rat was situated, came on and the door was opened. At the same time, the light in the original compartment went off. The animal had to enter the original compartment within $10 \mathrm{sec}$ to avoid footshock. Trials were scored as correct when the rat entered the safe compartment before the shock came on. Training sessions lasted about $40 \mathrm{~min}$.

All animals were given 2 days of training in the two-way shuttle shock-avoidance task ( 50 trials per day). Training time was always between 9:00 and 11:00 a.m. each day. On Training Day 2, the rats were required to get $60 \%$ of the last 20 trials correct or they were considered not to have learned the task. Six rats were discarded from the study in this way. The animals were then randomly assigned to one of seven groups ( $n=8$ per group). Several of the different test and control group animals were always run at the same time, to avoid having any one group in a single batch.

Following training, all groups were exposed to $4 \mathrm{~h}$ of PSD. The PSD occurred during Hours 49-52 (GR 49-52), 53-56 (GR 53-56), 57-60 (GR 57-60), 61-64 (GR 61-64), 65-68 (GR 65-68), or 69-72 (GR 69-72) after the end of the last training session. A control group (GRC) was never exposed to PSD.

All animals were retested 7 days after the end of the last training trial. This was considered to be ample time for recovery from any post PSD fatigue. At this time, the animals were given 20 additional retest trials.

\section{PS Deprivation}

The PSD periods were carried out to coincide with the time at which the training session for a particular animal had ended. The PSD apparatus has been described previously (Smith \& Young, 1980); basically, it involves the "swimming pool" technique, which requires the animal to sit on a small island $(8.5 \mathrm{~cm}$ in diameter) surrounded by water. In this situation, rats are unable to completely relax the large muscle groups (a necessary condition for PS to occur) without falling from the platform and getting wet. Because complete relaxation of the large muscle groups is not required for slowwave sleep (SWS), all animals were able to get some SWS. The previously completed recording study (Smith \& Lapp, 1986) indicated that the learning task resulted in independent increases in PS and that there were no changes in the amount of SWS during or after the training sessions. This is true of the great majority of the animal recording studies (Smith, 1985).

\section{RESULTS}

The groups were compared in a one-way analysis of variance ANOVA of the number of correct avoidances on the posttest scores of the 7 groups. A significant effect was found for groups $[F(6,49)=6.54, p<.01]$. The Newman-Keuls test of individual comparisons revealed that the GR 53-56 group had significantly lower posttraining scores than did any of the other groups $(p<$ .05 ). There were no other significant differences between any of the test or control groups. The results are shown in Figure 1.

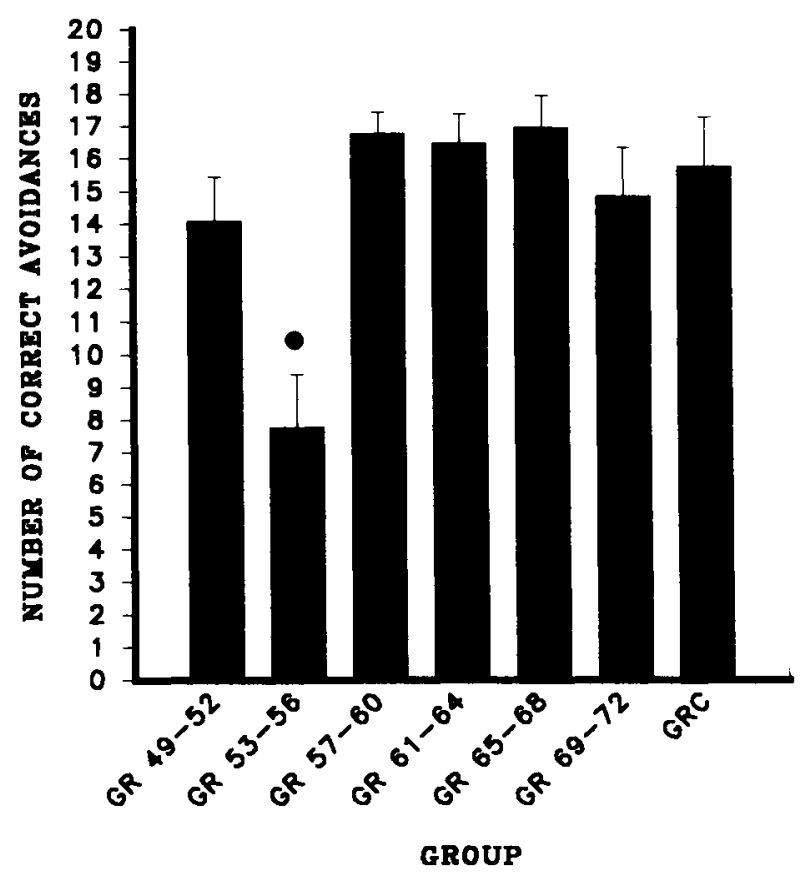

Figure 1. Mean number of correct avoidances 7 days after the last training trial. Bars represent SEM. -Significantly different from all other groups $(p<.05)$.

An ANOVA of the last 20 trials of Training Day 2 was also performed in order to be sure that the groups were not different before the PSD treatment. No significant overall difference was found in this analysis, indicating that the groups were not initially different. Both pre- and post-PSD scores for all the groups can be seen in Table 1.

\section{DISCUSSION}

As predicted, the length of the PSD necessary to induce deficits did not have to be $24 \mathrm{~h}$. The GR 53-56 group showed a $49 \%$ drop in correct performance in comparison with that of the GRC group. In the previous study, with a 24-h PSD applied during Hours 48-72 after training (Smith \& Kelly, 1988), the drop in performance in comparison with that of the control group was $48 \%$. Thus, it seems that the most effective time for the PSD to be applied was 53-56 $\mathrm{h}$ after the end of the last training trial and that PSD outside this time period had no effect whatsoever. This result strongly suggests that a PSW exists 53-56 $\mathrm{h}$ after training in the shuttle avoidance task when the Sprague-Dawley rat is used.

If we include the results of applying PSD in earlier work (Smith \& Lapp, 1986), we have the picture of a memory process that is vulnerable in the first $24 \mathrm{~h}$ after training (PSW during Hours 9-12) and then becomes vulnerable once again (PSW during Hours 53-56) after the end of the second training session.

In previous work (Smith \& Lapp, 1986), it was observed that a PS window existed during Hours 9-12 after 
Table 1

Means and Standard Deviations of the PSD Groups Showing the Values of the Last 20 Trials Prior to PSD (Pre-PSD) and the 20 Trials Following PSD (Post-PSD)

\begin{tabular}{lcccc}
\hline & \multicolumn{2}{c}{ Pre-PSD } & \multicolumn{2}{c}{ Post-PSD } \\
\cline { 2 - 4 } Groups & $M$ & $S D$ & $M$ & $S D$ \\
\hline GR 49-52 & 15.4 & 2.72 & 14.1 & 3.79 \\
GR 53-56 & 15.5 & 2.93 & $7.8 *$ & 4.59 \\
GR 57-60 & 16.2 & 3.42 & 16.8 & 1.83 \\
GR 61-64 & 17.6 & 2.25 & 16.5 & 2.56 \\
GR 65-68 & 16.8 & 3.94 & 17.0 & 2.78 \\
GR 69-72 & 15.7 & 3.31 & 14.9 & 4.16 \\
GRC & 16.4 & 2.07 & 15.8 & 4.33 \\
\hline
\end{tabular}

*Significantly different from all other post-PSD group values $(p<.05)$; see Results section.

the first 50 training trials. This window appeared to coincide with the beginning of the extra above-normal PS increases and was considered to be effective in interfering with memory processes, because the PSD was applied at the onset of the activity of an important memory-processing mechanism. PSD applied later, after this mechanism had been in action for some time, was not effective in disrupting memory. In this task, when training continues for a 2nd day (another 50 training trials), the PS drops to normal levels. PSD on this day does not result in any memory deficits. However, on Posttraining Day 1, the PS begins to increase again, over normal levels. In fact the largest increases in PS occur 4-5 days after the end of training (PT4 and PT5).

Since the present PSW occurs on Posttraining Day 2, it is not obviously at the beginning of any PS event. Furthermore, given the idea that the posttraining PS increases appear to be cyclic in nature in terms of the 24-h clock (Smith \& Lapp, 1986; Smith et al., 1980), the PSW during Hours 53-56 did not occur exactly where predicted. This suggests that the timing of the PSW is controlled by mechanisms other than the 24-h rhythm.

A neurochemical investigation of the rat brain has recently been done on the PSW during Hours 9-12 (Smith, Tenn, \& Annett, 1991). The activities of acetylcholine (ACh) and acetylcholinesterase (AChE) after training were found to be markedly increased over test-animal baseline levels and control-animal levels during the PSW from Hour 9 to Hour 12. Furthermore, the anticholinergic agent scopolamine, when injected to coincide with this window from Hour 9 to Hour 12, induced memory deficits. The same drug produced no deficit when administered either $4 \mathrm{~h}$ before or $4 \mathrm{~h}$ after this time period. Evidence strongly suggested that $\mathrm{ACh}$ was one of the active transmitters during the PSW from Hour 9 to Hour 12 (Smith et al., 1991). The nature of the biochemical activity in the PS window from Hour 53 to Hour 56 in the present study is unknown. It would seem possible that $\mathrm{ACh}$ would again be important for the normal memory processing of the avoidance task. However, confirmation of this idea must await further empirical study.
The PSW may reflect some kind of consolidation process. More traditionally, memory consolidation has been conceived as being fragile and vulnerable to disruption for a short period of time (minutes to hours) after acquisition and as then being converted to more stable, less vulnerable long-term memory (Levinthal, 1983; Tarpy. 1982). Because of this focus, relatively few studies have examined the possibility of the vulnerability of memory days and weeks after the end of training. One group that has looked at this possibility (Deutsch, 1983) found that memory processes were vulnerable to anticholinergic drugs 3-6 days after training in rats. Memory was not vulnerable to these agents either before or after this time period. The results were attributed to slow changes in postsynaptic conductivity, with the transmitter substance being ACh. These results could conceivably be related to the findings in the present study, because of the long posttraining timing of the vulnerable period and the possible involvement of $\mathrm{ACh}$.

Stress resulting from PSD has often been considered an alternative explanation for post-PSD performance. However, it is unlikely that the inferior performance of the GR 53-56 group could be due to stress, since all of the other groups were exposed to the same amount of stress while in the "swimming pool" situation. Furthermore, the amount of PSD was quite short $(4 \mathrm{~h})$, and the rats were all tested 1 week after the end of training, allowing approximately 5 days of normal rest following the PSD before the retest.

In summary, the vulnerability of the learned material to PSD so long after the end of training suggests that memory processing continues for a considerable period of time after training has ended. It also indicates that PS plays an important role in this processing. These results require the expansion of the concept of the PSW beyond the initial $24 \mathrm{~h}$ following training and allow us to state that there is a PSW during Hours 53-56 following the end of training in the shuttle avoidance task.

\section{REFERENCES}

BLoch, V. (1970). Facts and hypotheses concerning memory consolidation processes. Brain Research, 24, 561-567.

Deutsch, J. A. (1983). The cholinergic synapse and the site of memory. In J. A. Deutsch (Ed.), The physiological basis of memory (pp. 367-423). New York: Academic Press.

Fishbein, W., \& Gutwein, B. M. (1978). Paradoxical sleep and memory storage processes. Behavioral Biology, 19, 425-464.

LeVINTHAL, C. F. (1983). Introduction to physiological psychology (2nd ed.). Englewood Cliffs, NJ: Prentice-Hall.

MCGrath, M. J., \& CoHEN, D. B. (1978). REM sleep facilitation of adaptive waking behavior: A review of the literature. Psychological Bulletin, 85, 24-57.

Pearlman, C. (1979). REM sleep and information processing: Evidence from animal studies. Neuroscience \& Biobehavioral Reviews, 3, 57-68.

Smith, C. (1985). Sleep states and learning: A review of the animal literature. Neuroscience \& Biobehavioral Reviews, 9, 157-168.

Smith, C., \& KeLLY, G. (1988). Paradoxical sleep deprivation applied two days after the end of training retards learning. Physiology \& Behavior, 43, 213-216. 
Smith, C., \& LAPP, L. (1986). Prolonged increases in both PS and number of REMs following a shuttle avoidance task. Physiology and Behavior, 36, 1053-1057.

Smith, C., Tenn, C., \& Annett, R. (1991). Some biochemical and behavioural aspects of the paradoxical sleep window. Canadian Journal of Psychology, 45, 115-124.

SмIтh, C., \& YounG, J. (1980). Reversal of paradoxical sleep deprivation by amygdaloid stimulation during learning. Physiology \& Behavior, 24, 1035-1039.
Smith, C., Young, J., \& Young, W. (1980). Prolonged increases in paradoxical sleep during and after avoidance task acquisition. Sleep, $3,67-81$.

TARPY, R. M. (1982). Principles of animal learning and motivation. Glenview, IL: Scott, Foresman.

(Manuscript received September 4, 1992; revision accepted for publication February 9, 1993.)

\section{Erratum}

Marshall-Goodell, B., Kehoe, E. J., and Gormezano, I. Laws of the unconditioned reflex in the rabbit nictitating membrane preparation. Psychobiology, 1992, 20(3), 229-237-The authors of this paper should have been listed as: Beverly Marshall-Goodell, E. James Kehoe, Kim K. Kirkpatrick-Steger, and I. Gormezano. 